\title{
INTUIÇÃO, HEURÍSTICA E INSIGHT: Uma aproximação preliminar
}

\section{Christian Carlos Kuhn ${ }^{1}$}

RESUMO: Este artigo pretende apresentar uma análise introdutória aos conceitos de intuição sensivel, intuição heurística e insight, normalmente utilizados no senso comum como sinônimos. Pretendemos apresentar os diferentes contextos ou perspectivas filosóficas em que estes se encontram. $\mathrm{Na}$ história da Filosofia, o tema da intuição se apresentava entre os helenos, medievais, na modernidade no que poderia chamar de Romantismo e Idealismo alemães e, de modo especial, no que se poderia chamar de intuicionismo. É, pois, no contexto filosófico alemão que se desenvolveu a Psicologia em seus primeiros passos, de modo especial a Gestalt, uma corrente psico-filosófica que serviu de cenário para o desenvolvimento do conceito de Insight. É evidente que os fenômenos psíquicos e as questões epistemológicas, que ainda continuam a inquietar o homem na busca do conhecimento e do autoconhecimento, tenham um campo fenomênico em comum; ainda temos uma visão compartimentada do conhecimento, bem como tivemos nossa imaginação castrada pelos nossos moldes educacionais atuais. Tais conceitos parecem transpassar as circunscrições das disciplinas acadêmicas e métodos convencionais de pesquisa e produção científica. Mais que isso, a intuição, ou mais especificamente a intuição heurística estaria por traz das grandes descobertas científicas e fundamentações filosóficas acerca da natureza, da sociedade e do mundo, sem nunca ter se tornado objeto digno de atenção. Por esses motivos, uma pesquisa mais profunda acerca destes conceitos se faz necessária, prometendo um ambiente rico para a investigação filosófica.

Palavras Chave: Intuição; heurística; insight; imaginação; criatividade; inspiração; gênio.

ABSTRACT: This article aims to provide an introductory analysis on the concepts of sensible intuition, heuristic intuition and insight, usually used interchangeably on the common sense. We want to present the different contexts or philosophical perspectives they are included. In the history of philosophy, the subject of intuition presented itself among the Greeks, medieval, in modernity in Romanticism, German Idealism and especially in what might be called intuitionism. Especially in the German philosophical context is where psychology itself developed in its infancy and especially the Gestalt, a psycho-philosophical current that was the scene of the development on the Insight's concept. Clearly, psychic phenomena and epistemological issues that still continue to worry the man in search of knowledge and self-knowledge to have a phenomenal field in common, we still have a compartmentalised view of knowledge and had our imagination castrated by our current educational molds. These concepts seem to pierce the constituencies of academic disciplines and conventional research methods and scientific production. Moreover, intuition, or more specifically the heuristic intuition would be behind the great scientific discoveries and philosophical foundations of the nature, society and the world, without ever have become a central object of our attention. For these reasons,

\footnotetext{
${ }^{1}$ Mestrando do Programa de Filosofia na Unioeste Toledo/Paraná.
} 
further research on these concepts is necessary, promising a rich environment for philosophical inquiry.

Keywords: Intuition; heuristic; insight; imagination; criativity; inspiration; genius.

RESUMEN: Este trabajo busca presentar una análisis introductoria a los conceptos de intuición sensible, intuición heurística, e insight, a menudo utilizado en el senso común como sinónimos. Así objetivamos presentar los diferentes contextos o perspectivas filosóficas en que ellos fueran debatidos. En la Historia de la Filosofia el tema de la intuición se presentaba entre los helenos, medievales, en la modernidad en lo que se podría llamar de Romantismo y Idealismo germánicos y también el intuicionismo. Especialmente en el contexto filosófico germánico, donde se desarrollo la Psicologia en sus primeiros pasos, principalmente Gestalt, una corriente psico-filosofica que fue cenário del concepto de insight. Es claro, que los fenómenos psíquicos y cuestiones epistemológicas que aun move el hombre en busca del conocimiento tienen un campo fenoménico común, aun tenemos una visión compartida del conocimiento, bien como tuvimos nuestra imaginación castrada por los padrones educacionales actuales. Esos conceptos traspasan los límites de las disciplinas académicas y métodos convencionales de investigación y producción científica. Más que eso, la intuición, o mejor, la intuición heurística estructura los descubrimientos científicas y fundamentaciones filosóficas acerca de la naturaleza, de la sociedad y del mundo, si nunca tener si tornado objeto de atención. Por esos motivos, una investigación más profunda acerca de esos conceptos es necesaria.

Palabras-llave: Intuición, heurística, insight, imaginación, creatividad, inspiración, génio.

\section{UMA FUTURA APROXIMAÇÃo ENTRE A FILOSOFIA, AS CIÊNCIAS E AS ARTES?}

Algo muito comum nos livros didáticos de Filosofia é a distinção aparentemente nítida entre os níveis de conhecimento, a saber, o senso comum, o conhecimento científico e a sabedoria ou conhecimento filosófico. De fato, tanto a ciências exatas quanto a filosofia desenvolvem métodos próprios e uma linguagem por vezes rebuscada, se afastando consideravelmente do senso comum. Immanuel Kant, ao publicar sua complexa obra, Crítica da Razão Pura, parecia falar grego à comunidade da pacata cidade de Königsberg, e talvez até hoje não tenha sido totalmente compreendido em seus verdadeiros propósitos, assim como vários filósofos, artistas, cientistas e psicólogos. Mas há algo profundamente filosófico que continua perpassar a experiência comum, a psicologia, a filosofia, e até mesmo a ciência, que pode se resumir à seguinte questão: Qual a relação e distinção que pode haver entre o processo de criação artística, as "sacadas" ou "descobertas", tanto no meio científico quanto na experiência comum, e aquilo que se chama de intuição? Também 
poderíamos chamar isso de Insight? Como poderíamos compreender filosoficamente esses conceitos? Confesso que foi movido por essa inquietação é que passei a pesquisar o conceito de intuição em Kant, o que, a princípio, foi um choque, por perceber que era mais complexo do que imaginava já saber “intuitivamente". Para tratar desta problemática pretendo, a princípio, apresentar alguns esclarecimentos acerca do conceito de intuição sensível em Kant, trazendo à discussão o conceito psicológico de Insight e finalmente tratando do conceito de intuição heurística.

\section{UMA INTRODUÇÃO AO CONCEITO DE INTUIÇÃO EM KANT}

Intuição é um termo de origem latina (in tueri) que guarda o sentido de algo que se poderia chamar por analogia de uma "visão interior". Poderíamos questionar por que não seria a intuição algo como um sentido interno qualquer, ou um pressentimento em vez uma "visão" interior. O fato é que nossa cultura nos condicionou a supervalorizarmos o sentido da visão e o adotarmos como o sentido mais importante. Isso é muito comum até para Kant, que, em suas aulas de Antropologia, defendia a mesma posição. Ao tratar do sentido da visão, em sua Antropologia de um ponto de vista pragmático, Kant afirma ser esse o sentido mais nobre "por se distanciar do tato como sentido mais limitado, e por menos conter elementos relativos à sensação, mais se aproxima de uma intuição pura". (KANT, 2006, §19).

Na história da Filosofia, o tema da intuição se apresenta em vários contextos filosóficos: entre os gregos, medievais, na modernidade e contemporaneidade, no que poderia chamar de Romantismo e Idealismo alemães, e de modo geral no pós-kantismo. O termo alemão Anschauung, traduzido convencionalmente por intuição ${ }^{i}$ (etimologicamente ligado ao sentido da visão), tem sua origem no termo grego epibolé, que resumidamente pode significar uma "relação direta (sem intermediários) com um objeto qualquer; por isso, implica a presença efetiva do objeto.” (ABBAGNANO, 2000).

No período crítico, Kant contrapõe um intellectus ectypus, o único acessível ao homem, criador de formas, e, neste sentido, um compositor, por assim dizer, de um intellectus archetypus, criador do Ser, Deus. O conceito de intuição teria perpassado a história da filosofia desde os gregos até Kant, que julgou necessário distinguir uma intuição intelectual (divina) de uma intuição sensível (limitada aos sentidos humanos). Um intelecto arquetípico, como o nome sugere, tem livre acesso aos 
arquétipos universais, portanto, conhece as coisas tais como são em si mesmas (o Ser), além de poder criar, ao contrário do intelecto ectípico, que está preso ao mundo das aparências sensíveis e formas derivadas, necessitando por isso, recorrer a imagens, esquemas, símbolos, analogias, etc, para suprir suas limitações.

Para Kant, todo o material captado pelas experiências dos sentidos de algum modo é armazenado em uma espécie de "arquivo formal inconsciente" que é, contudo, acessível parcialmente pela consciência mediante o Entendimento e, embora seja um trabalho hercúleo, é indispensável para o autoconhecimento. Em suas aulas de Antropologia, o filósofo apresentava o homem como dotado de faculdades opostas, porém complementares: O Entendimento e a Sensibilidade ${ }^{i i}$. A primeira apresenta um aspecto ativo no conhecimento; a segunda, um aspecto receptivo. A analogia que Kant apresenta é que o Entendimento é como o Senhor e a Sensibilidade é como a Senhora. A intuição para o Homem é referente à Sensibilidade que, contudo, possui aspectos tanto empíricos, como puros. O primeiro se refere ao múltiplo das sensações e sentidos, tanto internos como externos. Ao segundo, Kant relaciona às formas a priori que antecedem e condicionam a experiência humana, que se referem em última instância às intuições de espaço e tempo. É, pois, justamente no aspecto meramente passivo da Sensibilidade que se deve as objeções que poderíamos ter a ela, como exemplo mais conhecido, a de que os sentidos enganam. No entanto, se há necessidade de imputar a confusão que eventualmente pode ocorrer no processo do conhecimento, Kant afirma que é ao Entendimento que se cabe. E este, que é faculdade do pensamento, dos conceitos, deve dominar a Sensibilidade sem, contudo, debilitá-la. Ao contrário, se é a Sensibilidade que passa a tomar as rédeas no conhecimento, esta poderá se tornar "a louca da casa" ou mais tragicamente, uma megera, levando-se inevitavelmente ao desvario.

Como bem se sabe, Kant apresenta a intuição intelectual (intelectus archetypus, conceito utilizado pelos metafísicos de sua época) como inacessível ao homem, mas nem por isso trancou as portas para a possibilidade de outros tipos de intuição ou faculdades anímicas. Uma das condições de possibilidades de desenvolvimento de uma intuição "mais objetiva" é tornar consciente aquilo que em nos é ainda inconsciente. Mas ao mesmo tempo parece que a natureza ou uma inteligência superior e originária nos fechou as portas para tais faculdades: 
Que seja imenso o campo das nossas sensações e intuições sensíveis, isto é, das representações obscuras no ser humano de que não somos conscientes ainda que possamos concluir indubitavelmente que as temos; (...) que, por assim dizer, no grande mapa de nosso espírito só haja poucos lugares iluminados, isso pode nos causar espanto com relação ao nosso próprio ser; pois bastaria apenas que um poder superior exclamasse: "faça-se a luz!", que, mesmo sem o acréscimo de quase nada,(...) meio mundo, por assim dizer, se abriria diante de nós. (KANT, 2009, §5, p.35).

Mais que isso, em suas aulas de Antropologia conseguia cativar seus alunos de forma notável com a profundidade e abrangência de seu intelecto analítico e crítico. Ademais, segundo Kneller, Kant pode ser incluído em uma corrente filosófica que poderíamos chamar de pré-Romantismo ${ }^{\mathrm{iii}}$, sobretudo por sua preocupação com a imaginação, com questões estéticas em geral e com o gênio ${ }^{i v}$. Por esses motivos, o pensador pode ser considerado um dos precursores da heurística contemporânea, se é que de fato há essa ciência ou disciplina. Apesar de seu estilo de escrita parecer por vezes obscuro, pesado e prolixo, e ter buscado formular um método filosófico novo, fundado em uma razão crítica e sistemática, a compreensão de seu método de escrita revela o verdadeiro gênio do Filósofo. Deixemos Kant concluir este primeiro tópico:

Devemos ter à mão uma folha de papel dobrada ao meio, na qual vamos registrando promiscue todas as imagens que digam respeito à matéria. Além disso, também precisamos fazer alguns intervalos enquanto pensamos, os quais contribuem de maneira extraordinária para o descanso e fortalecimento da imaginação. Também devemos evitar ler com frequência aquilo que nós mesmos tivermos escrito. (Não devemos ler escritos sobre a matéria que estamos refletindo, do contrário atamos o gênio.) E devemos pensar no assunto e reunir imagens. Quando ali se encontrarem todos os materiais de nosso assunto, surgirá em nós durante a leitura um esquema que formularemos em frases curtas, emendando-o sem coerção. Caso o esquema esteja correto, recorremos ao nosso estoque de imagens. Anotamos então a matéria sem ponderação, e se logo nos ocorre alguma coisa, deixamos um espaço e, com uma palavra, assinalamos na margem o que deverá vir no meio. Depois, nós o revemos, completamos aquilo que sentimos faltar, copiamos uma vez mais, polimos aqui e ali, e ele está pronto. Pensa algo disparatado e certamente falha em seu objetivo, quem quer fazer algo muito bem de uma só vez, intercalando aí os seus pensamentos (TERRA, 1995, p11).

\section{O CONCEITO DE INSIGHT}


É comum ouvir várias pessoas, em certas situações da vida, afirmarem que "tiveram a intuição de algo" ou que inesperadamente e inconscientemente tiveram um "insight" e imediatamente escreveram inspiradamente um texto filosófico-poético ou até mesmo solucionaram um problema aparentemente insolúvel. É simplesmente natural que no senso comum, se utilize de termos e conceitos sem o compromisso com a verdade, com um método específico ou com o mínimo de profundidade conceitual. Quando no dia-a-dia dizemos que tivemos um insight de algo, podemos ser compreendidos tranquilamente e, de fato, o próprio termo inglês proporciona uma compreensão básica no sentido de um "sentido interno". No entanto, é característica notável de um espírito filosófico e crítico o não contentamento com a superficialidade conceitual. Nesse sentido é necessário investigar outras perspectivas em que esse termo pode ser observado.

Um dos pioneiros na utilização do termo Insight foi Wolfgang Köhler, um psicólogo de uma vertente filosófico-psicológica singular: a Gestalttheorie ou Gestaltpsychologie. Poderíamos dizer provisoriamente que esses estudos consistem basicamente na busca de compreensão das estruturas que condicionam nossa percepção das "formas gerais" e "formas particulares", relativo, portanto, às configurações de nossas representações. Mas busquemos alguns dados mais concretos a respeito. Além do próprio Köhler, Koffka e Wertheimer podem ser considerados como seus grandes representantes. No ano de 1910, em uma viagem de trem de Viena para a Renânia, Max Wertheimer teve a seguinte experiência que o impulsionou no desenvolvimento dessa nova vertente:

Olhou para um sinal ferroviário que continha duas lâmpadas. Uma lâmpada se acendia e pouco depois se apagava. Após um tempo bem pequeno, a outra lâmpada passava pelo mesmo processo. Depois, novamente a primeira lâmpada se acendia e apagava, e assim por diante. As pessoas que olhavam para o arranjo, inclusive o próprio Wertheimer, viam apenas uma luz que ia, continuamente, no espaço entre as duas lâmpadas, para um lado e a seguir para o outro. Wertheimer ficou tão excitado com o que viu, que pensou na possibilidade de um experimento a respeito. Desceu do trem ao passar por Frankfurt, comprou cartolinas e um estroboscópio numa loja de brinquedos na cidade, alugou um quarto num hotel e começou a construir lá mesmo algumas figuras em duplicidade que deixassem a luz passar num tempo muito curto. Se a luz se acendesse e se apagasse numa figura e a seguir se acendesse e apagasse na outra, com intervalo entre eles de mais ou menos 60 milissegundos, enxergava-se apenas a figura indo de um lugar para outro. (ENGELMANN, 2002, p.01). 
Depois dessa experiência, entrou em contato com o Instituto de Psicologia local, onde estabeleceu um primeiro contato com Köhler. Improvisaram uma sala para os experimentos e fizeram as adaptações necessárias. Mais tarde, Köhler entrou em contato com Koffka e, após muitos testes, Wertheimer passou a trabalhar oficialmente no laboratório. Esses estudos consistem na busca de compreensão das estruturas que condicionam nossa percepção das "formas gerais" e "formas particulares", em uma área que transita entre a Psicologia, a Filosofia, a neurofisiologia, etc.

Wolfgang Köhler ${ }^{\mathrm{vi}}$, da Universidade de Berlin, desenvolveu uma série de estudos dos chimpanzés, a fim de avaliar suas possíveis faculdades cognitivas. Utilizou-se de vários instrumentos como canetas, caixas, palanques, varetas, etc, de modo a observar como seria a reação dos animais. Köhler construiu uma série problemas para os macacos envolvendo a obtenção de alimento, muitas vezes inacessíveis. Outros psicólogos já haviam realizado anteriormente experiências semelhantes com cães e gatos com resultados muitas vezes insatisfatórios. Considerando que era necessária uma adaptação suficiente dos animais às salas de experimentos, o experimento de Köhler se apresentou como mais promissor.

O estudioso chegou à conclusão de que tais experiências apontam inegavelmente para uma evidência de que os símios percebem uma determinação causal entre certos eventos ditos "externos" com eventos internos ou psico-fisiológicos, e que tal associação pode ser compreendida em termos de um Insight, um sentido interno que pressupõe planejamento. Assim Köhler se expressa: “(...) tomado em seu sentido básico, o termo discernimento (insight) refere-se à dinâmica experimentada nos campos emocional e de motivação não menos que à determinação experimentada em situações intelectuais". (KÖHLER, 1980, p.195). O psicólogo admite, portanto, que há uma dinâmica em uma instância representacional ampla que tanto os animais em geral quanto o homem possuem em comum. Talvez a grande dificuldade de se avaliar tais experiências é o constrangimento em se determinar exatamente em que consiste a Consciência e a Razão e sob que condições e relações o homem compartilha com os demais animais a mesmas capacidades cognitivas.

Desse modo as experiências tidas como inexplicáveis ou apenas desinteressantes para alguns homens de ciência, não o são para a Psicologia, nem para a Filosofia, segundo o pensador, ao contrário, o conceito de Insight é um dos mais importantes conceitos psicológicos. 


\section{INTUIÇÃo HEURÍSTICA}

Comecemos nos questionando acerca do significado do termo "heurística". O termo "heurística" tem sua origem etimológica no grego, heurísko, ou na famosa exclamação de Arquimedes ao compreender a dinâmica dos fluídos: "Eureka!" (achei, encontrei!). Podemos, ademais, encontrarmos vários sentidos muito semelhantes em contextos diferentes. ${ }^{\text {vii }}$ De acordo com exemplos anteriores, poderíamos nos perguntar afinal: Como poderíamos compreender o conceito de intuição em relação às descobertas científicas e soluções que surgem espontaneamente para problemas aparentemente insolúveis?

Podemos dizer que há inúmeras teorias ou métodos heurísticos que variam de acordo com a área em questão. Por exemplo, na matemática há algo conhecido como método ou heurística de Pólya, desenvolvida para se resolver problemas matemáticos. O próprio Kant, como apresentamos no início deste artigo, tinha um método próprio para escrever e filosofar.

Primeiramente, precisamos retomar que, para Kant, só temos intuições (em sentido superior) mediadas pelos sentidos. Isso permitiria dizer que para a maior parte dos estudiosos do assunto, não poderíamos sequer pensar em uma "intuição de tipo intelectual" ou "puramente objetiva, real".

Já, segundo Jacob Bazarian ${ }^{\text {viii }}$, há vários tipos de Intuição, dentre elas a intuição sensível, tratada de modo especial por Kant, a intuição intelectual tratada por Descartes (e que Kant, nega a possibilidade) e de modo geral pelos filósofos medievais, a intuição metafísica, intuição de evidência, e finalmente a intuição heurística, etc. E é sobre a última que iremos focar agora.

Se partirmos da premissa de que, de fato, a intuição pressupõe uma relação imediata entre sujeito e objeto, poderíamos questionar, afinal, em que sentido é imediata? Analisemos o seguinte exemplo. É muito comum se pensar que na composição musical, de modo mais específico a música clássica, se trata de um conhecimento complexo, rebuscado, erudito, etc. E é como aprender um novo idioma, com um léxico, uma gramática e uma escrita própria. De fato, se exige um grau de compreensão e sensibilidade estética diferente da música popular. Mas, ao contrário do que se possa pensar, os grandes mestres da música clássica como, Beethoven, Mozart, Bach, não compunham suas músicas como um matemático que calcula uma difícil equação, buscando encontrar as notas precisas 
para cada linha da pauta. Apesar de haver muita matemática na música e de modo geral na teoria musical, ao passar do tempo, se torna uma matemática intuitiva, muito próxima do que Kant chama de intuições puras. Os grandes mestres da música clássica, muitas vezes ouviam suas sinfonias quase prontas em suas mentes, e simplesmente as transcreviam ao papel.

A resposta mais plausível para nossa pergunta anterior é, a saber, que a intuição é imediata por não haver uma mediação da razão, e nesse sentido que, segundo Bazarian, consiste a intuição heurística, ou seja, "a solução intuitiva aparece de modo direto, imediato na consciência, isto é, sem os elos intermediários do raciocínio" (BAZARIAN, 1973, p.33).

Essa "faculdade" ou este fenômeno ainda pouco compreendido pelos cientistas, merece especial atenção, pois, de fato parece revelar um trabalho conjunto entre o consciente e o inconsciente e, desse modo, seria um conceito que transpassa as circunscrições das disciplinas acadêmicas e métodos convencionais de pesquisa e produção científica. Mais que isso, a intuição, ou mais especificamente a intuição heurística estaria por traz das grandes descobertas científicas e fundamentações filosóficas acerca da natureza, da sociedade e do mundo, sem nunca ter se tornado objeto digno de atenção.

O conceito de intuição possui um amplo escopo na história das ideias filosóficas e, segundo Bazarian, a maioria das escolas filosóficas do século XX são intuicionistas na medida em que conferem à intuição uma importância inegligenciável para o conhecimento. No entanto, ressalta a dificuldade em se encontrar uma definição convencional acerca deste tema na filosofia já que cada autor dá sua tonalidade conceitual singular a este conceito.

\section{CONSIDERAÇÕES FINAIS}

É certo que a linguagem de senso comum é marcada pela sua característica de irresponsabilidade conceitual, motivo pelo qual, às vezes, o uso de exemplos do senso comum para se explicar certos fenômenos naturais e psíquicos pode ser rechaçado veementemente em um círculo intelectual. Mas, podemos concluir que os três conceitos possuem algo em comum, uma vez que se remetem aos conteúdos internos de representação e, tanto intuição como Insight, apontam para um “sentido", percepções ou representações internas. 
O conceito de intuição em Kant, talvez o conceito sob o qual se funda sua crítica à metafísica de seu tempo, é de uma amplitude ainda não mensurada, dada a profundidade e diversidade de perspectivas que Kant pode ser compreendido. A relação entre intuição e visão, representações conscientes e inconscientes (ou obscuras) ainda há muito a explorar em Kant, bem como suas possíveis aproximações com a Gestalt. Por mais que não possamos tomar a intuição heurística no mesmo sentido de intuição sensível, tal como Kant a apresenta junto às suas objeções acerca dos limites de nossas faculdades de conhecimento, podemos encontrar novas e profundas reflexões acerca desses conceitos, respeitando a singularidade de cada pensador.

É evidente que certos fenômenos e questões epistemológicas que continuam a inquietar o homem na busca do conhecimento tenham um campo fenomênico em comum. Mas a visão compartimentada que temos do conhecimento e que condicionam nossos modelos educacionais atuais, bem como a visão tecnocrata que move as engrenagens ocultas de nossa sociedade ocidental atual castram nossa imaginação e criatividade, não nos permitindo encontrar outros meios de ampliarmos nossas faculdades de conhecimento, bem como desenvolver novas e mais abrangentes ciências, disciplinas e métodos intuitivos, livres de paradigmas e normas coercitivas.

\section{NOTAS}

i O substantivo feminino Anschauung possui conexão etimológica com o sentido da visão, tanto no alemão (Schauen) quanto no latim (in tueri), que pode ser compreendida como uma visão interior. Para se ter exemplos de uso desse termo alemão no senso comum, o dicionário escolar Michaelis apresenta algumas alternativas de termos que podem ser equivalentes ao termo alemão, como por exemplo: 1) Convicção; 2) Ponto de vista, opinião; 3) Impressão; 4) Ideia, noção, conceito; 5) Experiência; e, finalmente, em um contexto religioso ou místico: 5) Visão, contemplação, intuição. (KELLER, 2006, p.21)

ii Kant não concebia somente estas duas faculdades do espírito, como também a Razão, a Imaginação, o Juízo, etc. É necessário, também, a importante distinção entre a Sensibilidade enquanto "faculdade de intuições", sensações, e, portanto, referente aos sentidos, do "sentimento" propriamente dito, que é um conjunto de representações internas mais complexas, que abrange o campo emocional, embora se possa notar um parentesco evidente entre ambos.

iii Por mais que não se possa encontrar ainda no século XVIII e XIX um movimento histórico literário e cultural preciso, a que se poderia chamar de Romantismo, se poderia pensá-lo como em gestação na época de Kant, cujo expoente é a escola de Jena. Ao observarmos o estilo de escrita kantiano, se poderia compreender a admiração de Kant pelos "poetas românticos" e "pessoas de gosto", explícita em sua Antropologia, ou seja, a admiração de Kant por pensadores que detinham uma linguagem mais agradável ao leitor, ao sabor da imaginação, em contraste com o estilo denso e sistemático de Kant. A dificuldade maior que parece surgir ao se conceber um Kant romântico, além das questões conceituais históricas, defende Kneller, se deve à tendência de se classificar o Romantismo como "um misticismo irracional de herdeiros estranhos" (KNELLER, 2010, p.09), aparentemente muito distante do espírito crítico kantiano. Estes temas 
pertencem uma série de elementos supostamente periféricos que compõem a visão filosófica de Kant e que não podem ser negligenciados.

O conceito de gênio ainda é pouco explorado no Academicismo, que, de modo geral, tende a supervalorizar suas preocupações epistemológicas, sobretudo sua primeira Crítica (Crítica da Razão Pura), sobrepujando suas preocupações Antropológicas, Éticas, Gnosiológicas, Metafísicas, etc. vinculadas ao autoconhecimento, e as noções de "Transcendental" ou "Suprassensível", conceitos também custosos em Kant. O gênio, em Kant, carece de um maior aprofundamento, sobretudo, por que nos permite pensar a Arte como o produto de um trabalho conjunto entre consciente e inconsciente ou de uma inteligência natural por traz da composição artística, da inspiração e do devaneio poético.

Termo alemão que significa "formas". No entanto, poderíamos compreender por: "(1) a forma; (2) uma entidade concreta que possui entre seus vários atributos a forma". (Op. Cit. p.02)

vi Wolfgang Köhler, da Universidade de Berlin, é considerado um dos grandes expoentes da Gestalt, uma vertente da Psicologia ainda em gestação. A obra, considerada uma das mais polêmicas do autor, é a "The Mentality of Apes" de 1925, onde o pensador apresenta seu conceito de Insight para descrever sua compreensão acerca das experiências realizadas com macacos.

vii Contexto científico: "a ciência que tem por objetivo a descoberta dos fatos"; Contexto de problematização: "a arte de inventar, de fazer descobertas" ou "método de investigação baseado na aproximação progressiva de um dado problema"; e Contexto pedagógico: "método educacional que consiste em fazer descobrir pelo aluno o que se lhe quer ensinar". (HOUAISS, 2001, p. 1524).

viii Filósofo Armênio que obteve notável influência, sobretudo no Instituto de Filosofia de Moscou. O pensador buscou apresentar uma análise gnosiológica da Intuição e sua função no conhecimento que pode encontrada de modo resumido na obra que aqui se utiliza como referência.

\section{REFERÊNCIAS BIBLIOGRÁFICAS}

BAZARIAN, Jacob. Intuição Heurística. São Paulo: Alfa-Ômega, 1986.

ENGELMANN, Arno. A psicologia da gestalt e a ciência empírica contemporânea. Psicologia: Teoria e pesquisa. Volume 18, número1, Jan-Abr. 2002. Disponível em $<$ http://www.scielo.br/scielo.php?script=sci_arttext\&pid=s0102-37722002000100002 $>$. Último acesso em 18/06/2015 às 22:30.

HOUAISS, Antonio et al. Dicionário Houaiss da Língua Portuguesa. Rio de Janeiro, Objetiva, 2001, $1^{\mathrm{a}}$ ed., p. 1524.

KANT, Immanuel. Antropologia de um ponto de vista pragmático. São Paulo: Iluminuras, 2006

KÖHLER, Wolfgang. Psicologia da Gestalt. Belo Horizonte: Itatiaia.1980.

TERRA, Ricardo. Duas introduções a crítica do Juízo. São Paulo: Iluminuras, 1995.

\section{PARA SABer MAIS ONLINe:}


Kohler's Research on the Mentality of Apes. Disponivel em: http://www.pigeon.psy.tufts.edu/psych26/kohler.htm. Acesso em: 12/06/2015 às 10:00.

A psicologia da gestalt e a ciência empírica contemporânea. Disponível em: http://www.scielo.br/scielo.php?script $=$ sci_arttext\&pid=s0102-37722002000100002. Acesso em: 12/06/2015 às 11:00. 